\title{
Período de permanência de espermatozoides em glândulas hospedeiras de espermatozoides e glândulas infundibulares em codorna de corte
}

[Stay period of sperm in sperm-storage glands and in infundibular glands in quails]

\author{
J.L.P.S. Miranda ${ }^{1}$, P.R. Xavier ${ }^{2}$, G.A.B. Mahecha ${ }^{3}$, A.P. Marques Júnior ${ }^{1 *}$ \\ ${ }^{1}$ Escola de Veterinária - Universidade Federal de Minas Gerais - UFMG - Belo Horizonte, MG \\ ${ }^{2}$ Aluna de pós-graduação - Escola de Veterinária - UFMG - Belo Horizonte, MG \\ ${ }^{3}$ Instituto de Ciências Biológicas - UFMG - Belo Horizonte, MG
}

\begin{abstract}
RESUMO
Para determinar o tempo de permanência de espermatozoides nas glândulas hospedeiras de espermatozoides (GHEs) e nas glândulas infundibulares (GIs) de codorna de corte (Coturnix coturnix coturnix), foram utilizados 12 machos e 66 fêmeas, totalizando 78 codornas em fase reprodutiva. As fêmeas foram distribuídas em 11 grupos e acasaladas por 24 horas em gaiolas individuais. Os machos, utilizados de modo intercalado, foram separados do contato com as fêmeas e colocados em descanso. As aves do grupo-controle (G0 - seis fêmeas) foram abatidas no início do experimento, enquanto as 60 fêmeas acasaladas foram distribuídas em 10 grupos (G1 a G10, com seis fêmeas cada) e abatidas a cada período de 24 horas, de forma sequencial. Fragmentos foram obtidos da região uterovaginal e do infundíbulo e submetidos às análises histológica, histoquímica e histométrica com técnicas de rotina. Os resultados morfométricos mostraram que $46 \%$ das GHEs continham espermatozoides em seu lume no primeiro dia após o acasalamento, diminuindo gradativamente nos dias posteriores chegando a $3 \%$ no quinto dia. Nesse período, os espermatozoides ascendem em direção às GIs, onde permanecem viáveis e férteis por, pelo menos, 96 horas após deixarem as GHEs, possibilitando a postura de ovos férteis por 10 dias, em média, após o acasalamento.
\end{abstract}

Palavras-chave: codorna europeia, glândulas hospedeiras de espermatozoides, morfometria

\begin{abstract}
Sperm-Storage Tubules (SSPs) and Infundibular Tubules (ITs) are the structures responsible for sperm storage in the oviduct of birds, snakes, alligators and turtles after mating. Aiming to determine length of stay of sperm-storage tubules (SSPs) and infundibular tubules (ITs) cutting quail, Coturnix coturnix coturnix, we used 12 males and 66 females, totaling 79 quails in the reproductive phase. The females were allocated into 11 groups and mated for 24 hours in individual cages. The males used were merged and separated from contact with females and placed at rest. The poultry of the control-group (G0 six females) was slaughtered at the beginning of the experiment, the 60 previously mated females were allocated into 10 groups (G1 to G10, with six females each) and were slaughtered sequentially. On the 10 th day, the last group (G10) was shot. The fragments obtained from the utero-vaginal region and the infundibulum of each female underwent histological techniques, immunohistochemistry and morphometry routine. The morphometric results showed that GHEs had 46\% of the sperm in his heat on day 1 after mating, decreasing gradually in the after days reaching 3\% on day 5. At this time they increase toward the infundibular tubules, where they remain viable and fertile for at least another 96 hours (4 days) after leaving the SSPs, allowing these birds to lay fertile eggs for 10 days on average after mating.
\end{abstract}

Keywords: female, quail, sperm-storage tubule, spermatozoa, morphometry

Recebido em 15 de junho de 2012

Aceito em 22 de janeiro de 2013

*Autor para correspondência (corresponding author)

E-mail: ampinho@ufmg.br 


\section{INTRODUÇÃOO}

A criação da codorna europeia Coturnix coturnix coturnix tem aumentado no país nos últimos anos, em razão de seu rápido crescimento, precocidade na maturidade sexual e na produção, alta produtividade e necessidade de pequeno espaço para grandes populações (Albino et al., 2002). Essas aves são maiores do que as da subespécie japonesa, e a fêmea chega a pesar 280-300g (Albino e Barreto, 2003; Barreto et al., 2007). Existem escassas informações sobre o potencial reprodutivo dessa linhagem europeia, de dupla aptidão para corte e postura (Móri et al., 2005).

Os espermatozoides apresentam prolongada sobrevivência no oviduto das aves, o que possibilita a postura de ovos galados por período maior (Birkead e Moller, 1992; Mello, 2000). Isso é atribuído à presença das glândulas hospedeiras de espermatozoides (GHEs) e das glândulas infundibulares (GIs), ambas localizadas, respectivamente, nas pregas longitudinais da transição uterovaginal e no infundíbulo distal do oviduto (Rodrigues, 1996; Mello, 2000; Miranda et al., 2009).

Após cópula ou inseminação artificial, os espermatozoides ascendem em direção à junção uterovaginal, onde são armazenados nas GHEs por tempo variável, dependendo das espécies, do estádio reprodutivo e da idade (King et al., 2002). Estudos realizados em peru (Meleagris gallopavo), por Verma e Cherms (1965), mostraram que os espermatozoides podem permanecer cerca de 59 dias nas GHEs. Na galinha doméstica, eles permanecem férteis no interior do oviduto de 10 a 21 dias (Gilbert et al., 1968), ou 27 dias após a inseminação artificial (Fujii e Tamura, 1963). Nas GIs, os espermatozoides permanecem armazenados temporariamente, prontos para a fertilização imediatamente após a ovulação (Van Krey et al., 1967). As glândulas da junção uterovaginal são consideradas como o principal local de armazenamento de espermatozoides, pois estes atingem primeiro esta região, permanecem nela por tempo maior e são liberados continuamente em direção ao infundíbulo distal (Fujii e Tamura, 1963; Bobr et al.,1964). Moraes et al. (2009) consideraram as GIs como o mais importante sítio de armazenamento de espermatozoides, pois nessa região ocorre a fertilização.
A determinação do tempo de permanência dos espermatozoides nas GHEs e nas GIs, possibilitando a produção de ovos fertilizados por um período maior de tempo, facilitará que granjas de codorna de corte melhorem o padrão utilizado na reprodução destes animais, resultando na redução do número de reprodutores, com consequente diminuição de perdas de matrizes, por exemplo, por traumatismos na cabeça, por excesso de cópulas diárias, e em aumento da eficiência reprodutiva.Com este trabalho, objetivou-se quantificar o número de GHEs e GIs com espermatozoides até $\mathrm{o} 10^{\circ}$ dia após o acasalamento natural, associando-se ao período de fertilidade dos ovos coletados da codorna de corte (Coturnix coturnix coturnix).

\section{MATERIAL E MÉTODOS}

Foram utilizadas 78 codornas europeias (Coturnix coturnix coturnix), em fase anual de postura, 66 fêmeas e 12 machos. As aves foram mantidas em gaiolas individuais padronizadas, com $15 \mathrm{~cm}$ de comprimento e $13 \mathrm{~cm}$ de altura, onde receberam 17 horas de luz diária e ração e água ad libitum.

Antes de iniciar o experimento, aprovado pelo Comitê de Ética em Experimentação Animal UFMG (Protocolo No140/2008), houve a padronização dos grupos quanto ao manejo nutricional e à coleta de ovos, e os acasalamentos só se iniciaram após todos os animais estarem em postura A seleção dos machos ocorreu conforme sua capacidade de dominância em relação às fêmeas e à frequência com que cobriam as fêmeas durante duas horas, sendo selecionados machos que copularam com maior frequência neste período.

O experimento foi composto de 11 grupos (G0 a $\mathrm{G} 11)$. As aves do grupo-controle (G0), 6 fêmeas, foram abatidas no dia do início do experimento. Os grupos G1, G2, G3, G4, G5, G6, G7, G8, G9 e G10, constituídos de seis fêmeas e seis machos cada um, foram acasalados por 24 horas, em gaiolas individuais, utilizando-se seis machos, de modo intercalado, que foram separados do contato com as fêmeas e colocados em descanso. O abate das matrizes do G1 ( $\mathrm{n}=6$ fêmeas) ocorreu no $10^{\circ}$ dia (240 horas) após o acasalamento; G2 $(n=6)$, no nono dia (216 horas) após o acasalamento; G3 (n=6), no oitavo 
dia (192 horas) após o acasalamento; G4 (n=6), no sétimo dia (168 horas) após o acasalamento; G5 ( $\mathrm{n}=6)$, no sexto dia (144 horas) após o acasalamento; G6 ( $\mathrm{n}=6)$, no quinto dia (120 horas) após o acasalamento; G7 (n=6), no quarto dia (96 horas) após o acasalamento; G8 $(\mathrm{n}=6)$, no terceiro dia (72 horas) após o acasalamento; G9 $(n=6)$, no segundo dia (48 horas) após o acasalamento; G10 ( $n=6)$, no primeiro dia (24 horas) após o acasalamento.

As aves foram abatidas por deslocamento cervical e submetidas à dissecação para localizar a região da junção uterovaginal e do infundíbulo distal do oviduto. Essa região foi aberta dorsalmente, e as pregas da mucosa das duas regiões foram contadas. A seguir, retiraram-se fragmentos longitudinais destinados a análises histológicas, que foram fixados em líquido de Bouin (Lillie e Fullmer, 1976) durante 24 horas e, depois, incluídos em parafina, cortados de forma semisseriada com $5 \mu \mathrm{m}$ de espessura e corados com hematoxilina e eosina, azul de toluidina $0,5 \%$ e borato de sódio $1 \%$.

Alguns fragmentos foram submetidos à coloração histoquímica pelo reativo de Schiff (PAS) (McManus, 1946) pelo alcian blue em $\mathrm{pH}$ 0,5 (Lev e Spicer, 1964), alcian blue em pH 2,5 (Mowry, 1956) e digestão pela amilase salivar, seguida de PAS (Michalany, 1980). Para estimar o número de glândulas de cada fêmea, foram contadas as secções transversais de três pregas da transição uterovaginal e do infundíbulo distal. A média dessas contagens foi multiplicada pelo número de pregas encontradas em cada região, obtendo-se o número médio de GHEs e GIs. Foram medidos o diâmetro externo, o diâmetro interno e a altura celular, e contados o número de células por glândula ao longo das três pregas da região uterovaginal e do infundíbulo distal. Essas medidas foram realizadas utilizando-se régua micrométrica com escala conhecida, acoplada à lente ocular de um microscópio de luz. O cálculo da altura do epitélio glandular foi realizado subtraindo-se do diâmetro glandular o diâmetro do lúmen, dividido por dois. O número de células de cada secção foi registrado por meio da contagem de seus núcleos.

Para verificar a significância das diferenças encontradas nas mensurações, foi feita análise descritiva das variáveis por meio da média, mediana e erro-padrão, e realizados o teste Wilcoxon entre GHEs e GIs. Valores de $\mathrm{P}<0,05$ foram considerados significativos (Sampaio, 1998).

\section{RESULTADOS E DISCUSSÃO}

$\mathrm{Na}$ junção uterovaginal do oviduto e no infundíbulo distal, o epitélio encontrado foi o pseudoestratifidado prismático, formado por células ciliadas e não ciliadas que se alternam. Semelhante descrição foi encontrada no epitélio de codorna e de perdiz por Rodrigues (1996) e Mello (2000), respectivamente, não havendo formação de ductos diferenciados em nenhuma dessas espécies. As GHEs e as GIs encontravamse distribuídas ao longo das pregas da junção uterovaginal e do infundíbulo distal, em arranjo desordenado (Fig. 1A e D), semelhantemente às descrições realizadas por Bakst (1994;1998), Freedman et al. (2001), Miranda et al. (2009) e Moraes et al. (2009). Algumas pregas apresentaram maior concentração de GHEs e de GIs em relação às outras, e, mesmo dentro de uma prega, foram encontradas regiões com densidade maior de GHEs e de GIs do que em outra. Este resultado assemelha-se ao descrito por Miranda et al. (2009) em peru caipira e difere dos relatos de Birkead e Moller (1992), que descreveram, no peru, que a região intermediária das pregas da junção uterovaginal apresenta maior concentração de GHEs do que as regiões das extremidades.

O epitélio das GHEs e GIs mostrou-se formado por células prismáticas, não ciliadas, com núcleo basal, vesiculoso, elíptico, com nucléolo evidente (Fig. 1B-F). O citoplasma das células glandulares era acidófilo, com a superfície apical apresentando trama terminal e projeções apicais sob a forma de microvilos, formando a borda estriada, vista por meio do microscópio óptico, semelhantemente ao descrito por Rodrigues (1996), Freedman et al. (2001), Miranda et al. (2009) e Moraes et al. (2009). As GHEs e as GIs, formadas por dois tipos celulares distintos, denominados de células claras e escuras, mostraram predomínio de células claras durante o período analisado, semelhantemente ao descrito por Rodrigues (1996) em codornas, Mello (2000) em perdizes e Miranda et al. (2009) em peru caipira. 

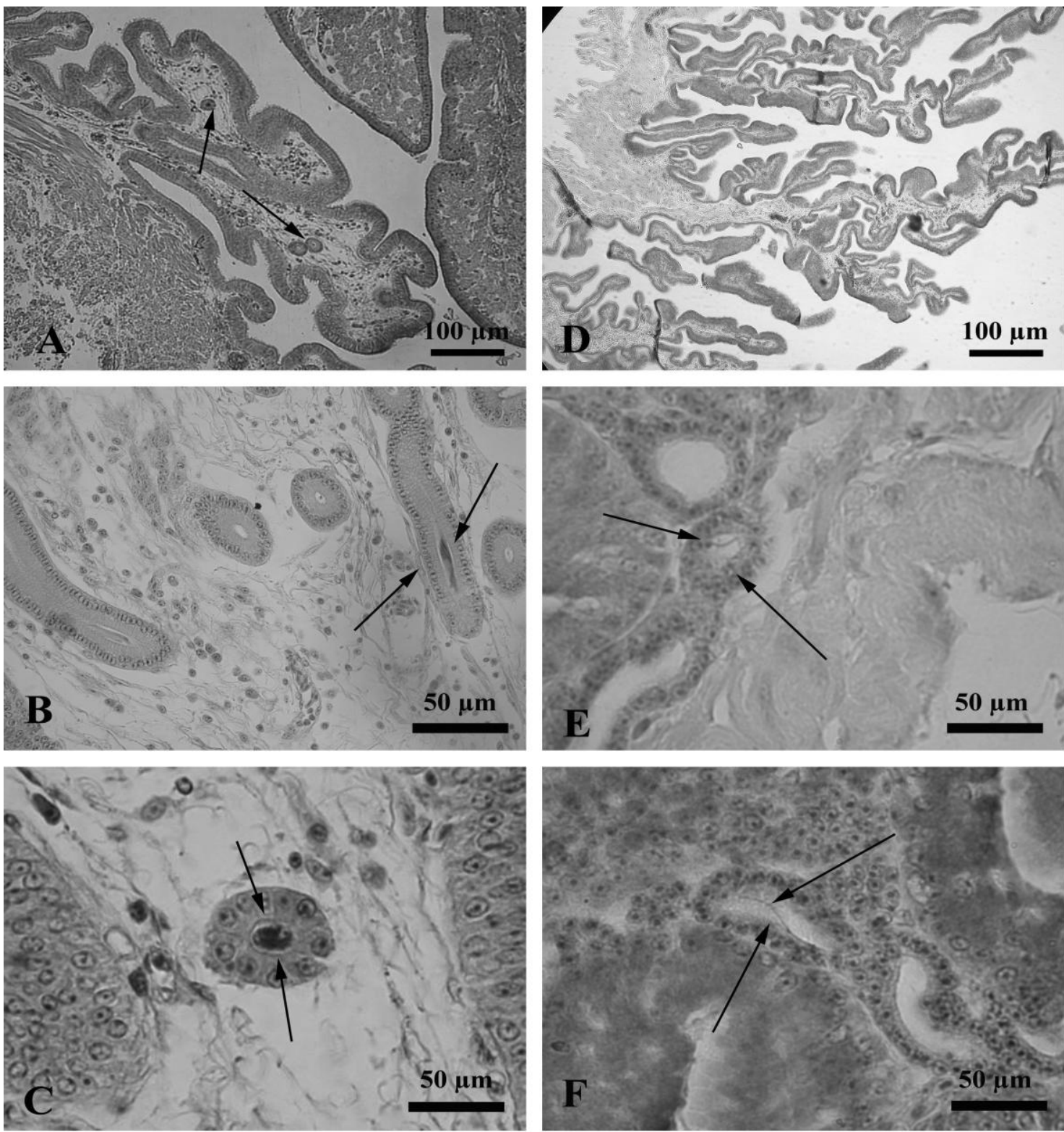

Figura 1. Codorna. Aspectos morfológicos das glândulas hospedeiras de espermatozoides (GHEs) na região da junção uterovaginal e das glândulas infundibulares (GIs) da codorna europeia Coturnix coturnix coturnix, durante o período de postura. A: aspecto geral das pregas da região uterovaginal, evidenciando pregas uterinas e pregas da junção uterovaginal, em fase de postura. Observam-se as GHEs (setas) em diferentes cortes transversais dispersos na lâmina própria. B: GHEs em secções longitudinais (setas) e transversais com espermatozoides (setas) no lume. C: detalhe de uma GHEs em secção transversal repleto de espermatozoides em seu lume (setas). D: aspecto geral das pregas do infundíbulo distal. E: GIs em secções longitudinais e transversais na lâmina própria; GI em secção transversal com um espermatozoide no lume. F: detalhe de duas GIs em secções longitudinais com espermatozoides no lume de uma das glândulas (setas). HE - A,D: 100X; B,E,F: 400X; C: 800X.

A natureza química das secreções das células das GHEs e das GIs não foi confirmada por meio de reações negativas aos métodos do ácido periódico-reativo de Schiff (PAS), após a digestão pela amilase salivar e pelo método de alcian blue em pH 0,5 e 2,5, indicando ausência de mucossubstâncias carboxiladas, sulfatadas e glicoproteínas, ricas em ácido siálico, 
semelhantemente ao relatado na galinha doméstica (Gilbert et al., 1968), em codorna comum (Rodrigues, 1996) e em peru caipira (Miranda et al., 2009).

Nas GHEs e nas GIs não foram encontradas vesículas vacuolizadas no citoplasma, em posição supranuclear, como descrito por Miranda et al. (2009) em peru. Estudos histológicos e histoquímicos demonstraram a presença de substâncias lipídicas nessas vesículas (Schupping et al., 1983) em peruas. É provável que o xilol utilizado nas preparações histológicas, no presente experimento, tenha retirado as gotículas lipídicas dessas vesículas, como descrito por Tingary e Lake (1973). Pal (1977) em patos, Renden et al. (1981) em codornas e Schupping et al. (1983) em peruas relataram a presença de vesículas vacuolizadas no citoplasma das células das GHEs em posição supranuclear, durante o período de postura, descritas por Friess et al. (1978), em galinhas e codornas, como vesículas cheias de gotículas lipídicas. Miranda et al. (2009) descreveram que essas vesículas só estão presentes no citoplasma das glândulas durante a fase de postura.
Nos resultados histoquímicos deste experimento e nos de outros autores (Birkead et al., 1990; Baumel et al., 1993; King et al., 2002; Miranda et al., 2009), não ficou demonstrado que estas estruturas têm a capacidade de secretar substâncias que possam nutrir os espermatozoides. Entretanto, observou-se que os espermatozoides armazenados nas GHEs conservaram sua vitalidade, pois foram capazes de fecundar durante o ciclo diário de ovulações, por 10 dias após o acasalamento. Não foi utilizado o termo "tubuli spermatici", recomendado pela Nomina Anatomica Avium (King, 1993) e adotado por Miranda et al. (2009) em peru, por se considerar que as GHEs têm a capacidade de secretar substâncias que possam nutrir os espermatozoides de uma forma não conhecida (Gilbert et al., 1968).

Estudo histomorfométrico realizado nas GHEs e nas GIs (Tab. 1 e 2) mostrou que as GIs são menores do que as GHEs em relação aos diâmetros externo e interno, à altura celular e ao número de células por glândula.

Tabela 1. Dados morfométricos de glândulas hospedeiras de espermatozoides (GHEs) (Média e desviopadrão) de codornas europeias (Coturnix coturnix coturnix), durante o período de postura

\begin{tabular}{rcccc}
\hline \multicolumn{1}{c}{ De* $^{*}$} & $\mathrm{D}$ i $^{*}$ & $\mathrm{NC}$ & $\mathrm{AC}$ \\
G9 & $38,25 \pm 3,52$ & $6,17 \pm 0,04$ & $19,34 \pm 5,77$ & $16,04 \pm 1,64$ \\
G8 & $39,13 \pm 2,68$ & $6,19 \pm 1,48$ & $20,00 \pm 2,95$ & $16,46 \pm 1,09$ \\
G7 & $39,05 \pm 3,00$ & $5,97 \pm 1,36$ & $19,86 \pm 2,58$ & $16,53 \pm 1,47$ \\
G6 & $38,72 \pm 3,95$ & $6,86 \pm 1,74$ & $20,77 \pm 3,57$ & $15,92 \pm 1,57$ \\
G5 & $36,46 \pm 4,40$ & $6,04 \pm 2,47$ & $19,27 \pm 5,94$ & $14,99 \pm 2,00$ \\
G4 & $38,57 \pm 4,14$ & $6,71 \pm 1,7$ & $20,08 \pm 4,17$ & $15,93 \pm 4,17$ \\
G3 & $38,82 \pm 4,04$ & $6,3 \pm 1,6$ & $18,91 \pm 3,17$ & $16,22 \pm 3,17$ \\
G2 & $37,9 \pm 4,2$ & $6,42 \pm 1,8$ & $18,22 \pm 4,27$ & $15,83 \pm 4,08$ \\
G1 & $38,21 \pm 4,5$ & $6,41 \pm 1,7$ & $18,43 \pm 4,19$ & $15,93 \pm 4,19$ \\
\hline Média total & $37,7 \pm 3,94$ & $5,91 \pm 1,7$ & $18,04 \pm 3,97$ & $15,93 \pm 4,07$ \\
\hline
\end{tabular}

* Diâmetro médio externo (De), diâmetro médio interno (Di), número de células (NC) e altura celular (AC) em $\mu \mathrm{m}$.

** G1, abate no $10^{\circ}$ dia (240 horas) após o acasalamento; G2, no nono dia (216 horas) após o acasalamento; G3, no oitavo dia (192 horas) após o acasalamento; G4, no sétimo dia (168 horas) após o acasalamento; G5, no sexto dia (144 horas) após o acasalamento; G6, no quinto dia (120 horas) após o acasalamento; G7, no quarto dia (96 horas) após o acasalamento; G8, no terceiro dia (72 horas) após o acasalamento; G9, no segundo dia (48 horas) após o acasalamento; G10, no primeiro dia (24 horas) após o acasalamento. 


\section{Miranda et al.}

Tabela 2. Dados morfométricos das glândulas infundibulares (GIs) (média e desvio-padrão) de codorna europeia (Coturnix coturnix coturnix), durante o período de postura

\begin{tabular}{|c|c|c|c|c|}
\hline & $\mathrm{De}^{*}$ & Di* & $\mathrm{NC}^{*}$ & $\mathrm{AC}^{*}$ \\
\hline$* * \mathrm{G} 3$ & $16,52 \pm 1,81$ & $6,31 \pm 1,5$ & $11,57 \pm 1,56$ & $5,89 \pm 0,88$ \\
\hline G4 & $15,87 \pm 1,23$ & $5,62 \pm 1,26$ & $9,25 \pm 1,21$ & $5,66 \pm 0,95$ \\
\hline G5 & $15,57 \pm 1,33$ & $5,42 \pm 1,16$ & $9,10 \pm 1,11$ & $5,06 \pm 0,65$ \\
\hline G6 & $18,65 \pm 1,54$ & $6,75 \pm 1,07$ & $11,94 \pm 1,56$ & $5,69 \pm 0,70$ \\
\hline G7 & $16,32 \pm 1,61$ & $6,01 \pm 1,2$ & $11,27 \pm 1,66$ & $5,14 \pm 0,68$ \\
\hline G8 & $16,77 \pm 1,71$ & $6,2 \pm 1,34$ & $11,48 \pm 1,66$ & $5,31 \pm 0,8$ \\
\hline G9 & $16,3 \pm 1,75$ & $5,54 \pm 1,26$ & $10,54 \pm 1,45$ & $5,42 \pm 0,79$ \\
\hline G10 & $16,14 \pm 1,83$ & $5,65 \pm 1,45$ & $9,89 \pm 1,73$ & $5,24 \pm 0,64$ \\
\hline Média Total & $16,51 \pm 1,60$ & $5,93 \pm 1,23$ & $10,63 \pm 1,49$ & $5,42 \pm 0,76$ \\
\hline
\end{tabular}

O acompanhamento diário dessas glândulas, por microscopia óptica, após o acasalamento natural, mostrou que o número de espermatozoides diminui gradativamente com o passar dos dias. $\mathrm{O}$ estudo histomorfométrico mostrou que $46 \%$ das GHEs continham espermatozoides em seu lume no primeiro dia após o acasalamento. Esta porcentagem diminuiu gradativamente nos dias posteriores, $44 \%$ no segundo dia, $14 \%$ no terceiro dia, $4 \%$ no quarto dia e $3 \%$ no quinto dia, após o acasalamento (Tab. 2 e Tab. 3).

Tabela 3. Porcentagem de glândulas hospedeiras de espermatozoides (GHEs) com espermatozoides de codorna europeia (GEs) (Coturnix coturnix coturnix), durante o período de postura

\begin{tabular}{ccccc}
\hline$* *$ G10 & GHEs & GEs* & \% de GEs \\
& & 1200 & 556 & 46 \\
& G9 & 2338 & 1042 & 44 \\
& G8 & 1316 & 196 & 4 \\
G7 & 1336 & 66 & 3 \\
G6 & 1156 & 36 & 0 \\
G5 & 1178 & 0 & 0 \\
G4 & 1535 & 0 & 0 \\
G3 & 1512 & 0 & 0 \\
G2 & 1514 & 0 & 0 \\
\hline
\end{tabular}

\footnotetext{
*GEs : GHEs com espermatozoides.
}

** G1, abate no $10^{\circ}$ dia (240 horas) após o acasalamento; G2, nono dia (216 horas) após o acasalamento; G3, oitavo dia (192 horas) após o acasalamento; G4, sétimo dia (168 horas) após o acasalamento; G5, sexto dia (144 horas) após o acasalamento; G6, quinto dia (120 horas) após o acasalamento; G7, quarto dia (96 horas) após o acasalamento; G8, terceiro dia (72 horas) após o acasalamento; G9, segundo dia (48 horas) após o acasalamento; G10, primeiro dia (24 horas) após o acasalamento. 
No sexto dia após o acasalamento, não foram encontradas glândulas com espermatozoides nesta região, mas ovos férteis foram postos até o $10^{\circ}$ dia após o acasalamento (Tab.4), achado não mencionado na literatura. Estudos realizados em peru mostraram que essas aves colocam ovos férteis por 59 dias após o acasalamento (Verma e Cherms, 1965) e que na galinha doméstica os espermatozoides permanecem férteis no interior do oviduto por 10 a 21 dias (Gilbert et al., 1968), ou 27 dias após a inseminação artificial (Fujii e Tamura, 1963).

Tabela 4. Fertilidade dos ovos postos por codorna europeia* (Coturnix coturnix coturnix), durante 15 dias

\begin{tabular}{cccccccccccccccc}
\hline Dias & $1^{\circ}$ & $2^{\circ}$ & $3^{\circ}$ & $4^{\circ}$ & $5^{\circ}$ & $6^{\circ}$ & $7^{\circ}$ & $8^{\circ}$ & $9^{\circ}$ & $10^{\circ}$ & $11^{\circ}$ & $12^{\circ}$ & $13^{\circ}$ & $14^{\circ}$ & $15^{\circ}$ \\
\hline Férteis & 0 & 2 & 29 & 27 & 25 & 21 & 20 & 18 & 17 & 15 & 11 & 8 & 2 & 0 & 0 \\
Não férteis & 30 & 28 & 1 & 3 & 5 & 9 & 10 & 12 & 13 & 15 & 19 & 22 & 28 & 30 & 30 \\
\hline
\end{tabular}

* Cada codorna permaneceu com um macho em gaiolas individuais por 24 horas.

Estudo morfométrico realizado nas GIs mostrou que elas armazenam, temporariamente, pequena quantidade de espermatozoides no lume (isto é: $0 \%$ no primeiro dia; $9,1 \%$ no segundo dia; $14 \%$ no terceiro dia; $20,9 \%$ no quarto dia; $17,8 \%$ no quinto dia; $9,4 \%$ no sexto dia; $5 \%$ no sétimo dia; $4 \%$ no oitavo dia; $2 \%$ no nono dia e $0,5 \%$ no $10^{\circ}$ dia) após o acasalamento (Tab. 5).

Tabela 5. Porcentagem de glândulas infundibulares (GIs) com espermatozoides de codorna europeia (GIEs) (Coturnix coturnix coturnix), durante o período de postura

\begin{tabular}{ccccc}
\hline \multirow{2}{*}{$* *$ GIs } & GIEs* & \% de GIEs \\
\hline & & 334 & 0 & 0 \\
& G9 & 348 & 32 & 9,1 \\
G8 & 343 & 32 & 14 \\
G7 & 339 & 71 & 20,9 \\
G6 & 337 & 60 & 17,8 \\
G5 & 318 & 30 & 9,4 \\
G4 & 328 & 17 & 5 \\
G3 & 340 & 14 & 4 \\
G2 & 322 & 7 & 2 \\
G1 & 335 & 2 & 0,5 \\
\hline
\end{tabular}

*GIEs : GIs com espermatozoides.

** G1, abate no $10^{\circ}$ dia (240 horas) após o acasalamento; G2, nono dia (216 horas) após o acasalamento; G3, oitavo dia (192 horas) após o acasalamento; G4, sétimo dia (168 horas) após o acasalamento; G5, sexto dia (144 horas) após o acasalamento; G6, quinto dia (120 horas) após o acasalamento; G7, quarto dia (96 horas) após o acasalamento; G8, terceiro dia (72 horas) após o acasalamento; G9, segundo dia (48 horas) após o acasalamento; G10, primeiro dia (24 horas) após o acasalamento.

Com base nestes resultados, pode-se inferir que os dois locais de armazenamento de espermatozoides no oviduto são sincrônicos. Após o acasalamento, os espermatozoides, depositados no fundo da vagina, ascendem em direção à região da junção uterovaginal, onde são armazenados em maior quantidade. Posteriormente, são liberados continuamente para o infundíbulo distal, onde permanecem armazenados de modo temporário nas GIs, onde ocorre a capacitação e a fertilização diária dos óvulos. Na literatura consultada, não foi encontrada menção a esta evolução (GoodrichSmith e Marquez, 1978; Bakst, 1994;1998; Moraes et al., 2009).

$\mathrm{Na}$ Tab. 3, observa-se que, no G9, os animais tinham número expressivamente maior de GHEs na junção uterovaginal em relação aos outros grupos. Na Tab. 4, o G9 apresentou número de 
GIs semelhante aos demais grupos. Estes resultados sinalizam para a necessidade de essa linhagem passar por um processo de seleção para elevar seu potencial reprodutivo, semelhantemente ao que ocorreu com perus industriais, que apresentam, hoje, elevado potencial reprodutivo (Miranda et al., 2009).

Apesar de as GIs armazenarem poucos espermatozoides, elas possibilitam que ovos férteis sejam produzidos por mais quatro ou cinco dias após as GHEs terem liberado todos os espermatozoides, aspecto não descrito em outras espécies pesquisadas (Bakst, 1994;1998; Mello, 2000; Moraes et al., 2009).

O local onde os espermatozoides permanecem armazenados no interior do oviduto foi abordado por Van Drimmlen (1946) e Bobr et al. (1964) em galinhas, por Bakst $(1994 ; 1998)$ e Miranda et al. (2009) em peru, por Mello (2000) em perdiz e por Moraes et al. (2009) em codorna japônica. Entretanto, existem discordâncias por parte dos autores sobre qual é o principal local de armazenamento de espermatozoides no oviduto de aves. Van Drimmlen (1946) e Moraes et al. (2009) descreveram que o infundíbulo distal é o principal local de armazenamento de espermatozoides no oviduto, pois número considerável de espermatozoides atinge as GIs e ali permanecem armazenados. Moraes et al. (2009) descreveram que o número de GIs na codorna japônica é maior do que o número de GHEs. Tendo em vista que o número de GHEs bem como sua quantidade nesta região e a própria organização dos espermatozoides nelas são superiores aos encontrados nas GIs na codorna europeia, as GHEs seriam o sítio primário de armazenamento de espermatozoides. Posteriormente, estes são liberados para as GIs, onde permanecem, capacitando-se e possibilitando a ocorrência das fecundações. Portanto, as GIs poderiam ser consideradas como sítio secundário de armazenamento de espermatozoides.

O número consideravelmente maior de GHEs com espermatozoides foi observado por Fujii e Tamura (1963) em galinhas, os quais também descreveram que as GHEs armazenam os espermatozoides por tempo maior que as GIs, mostrando que a junção uterovaginal é o sítio primário de armazenamentos de espermatozoides no oviduto. No presente trabalho, os resultados mostraram que, na codorna europeia, os espermatozoides não permanecem um tempo maior nas GHEs, apenas permanecem armazenados temporariamente na região do infundíbulo distal para a fecundação dos óvulos, em pequena quantidade, durante o ciclo diário de ovulações. Entretanto, há necessidade de mais estudos para confirmar este achado e também para se avaliar qual seria o fator responsável pela sobrevivência dos espermatozoides nesses reservatórios.

A partir dos resultados, é plausível afirmar que a codorna europeia (Coturnix coturnix coturnix) tem grande potencial reprodutivo e de produção, além de apresentar, em média, o dobro do peso da linhagem de postura Coturnix coturnix japonica e de manter as características dessa linhagem quanto a postura e fertilidade dos ovos.

Os resultados do presente trabalho representam uma contribuição para nortear estudos sobre a inseminação artificial desta espécie, em matrizeiros, uma vez que nestes processos é utilizado sêmen de alta fertilidade, além de fornecer subsídios para estudos comparativos com outras espécies de aves.

\section{CONCLUSÕES}

$\mathrm{Na}$ codorna Coturnix coturnix coturnix, as glândulas hospedeiras de espermatozoides armazenam espermatozoides por um período de até 120 horas, os quais delas se deslocam, por movimento ascendente, em direção às glândulas infundibulares, onde permanecem viáveis e férteis por, pelo menos, 96 horas, possibilitando a produção de ovos férteis por 10 dias após o acasalamento.

\section{AGRADECIMENTOS}

Ao CNPq, pelo Grant concedido ao pesquisador, o qual possibilitou a realização do experimento. 


\section{REFERÊNCIAS}

ALBINO, L.F.T.; BARRETO, S.L.T. Criação de codornas para produção de ovos e carnes. Viçosa, MG: Aprenda Fácil, 2003, 289p.

ALBINO, L.F.T; PINTO, R.; FERREIRA, A.S. et al. Níveis de proteínas e energia para codornas japônicas em postura. Rev. Bras. Zootec., v.31, p.1761-1770, 2002.

BAKST, M.R. Fate of fluorescent stained sperm following insemination: New Light on oviductal sperm transport and storage in the turkey. Biol. Reprod., v.50, p.987-992, 1994.

BAKST, M.R. Structure of the avian oviduct with emphasis on sperm storage in poultry. $J$. Exp. Zool., v.282, p.618-626, 1998.

BARRETO, S.L.T; QUIRINO, B.J.S.; BRITO, C.O. et al. Efeitos de níveis nutricionais de energia sobre o desempenho e a qualidade de ovos de codornas europeias na fase inicial de postura. Rev. Bras. Zootec., v.36, p.86-93, 2007.

BAUMEL, J.J.; KING, A.S.; BREAZILE, J.E.; et al. Handbook of Avian Anatomy: Nomina Anatomica Avium. 2nd. ed., n.23, Cambridge, Mass.: Nuttall Ornithological Club, 1993. 799p.

BIRKEAD, T.R.; PELLAT, J.E.; HUNTER, F.M. Numbers and distribution of sperm in the uterovaginal sperm storage of the Zebra Finch. Condor, v.92, p.508-516, 1990.

BIRKEAD, T.R.; MOLLER, A.P. Sperm Competition in Birds: Evolutionary causes and consequences. London: Academic, 1992. 288p.

BOBR, L.W.; LORENZ, F.W.; OGASAWARA, F.X. Distribution of spermatozoa in the oviduct and fertility in domestic birds. 1. Residence sites of spermatozoa in fowl oviducts. J. Reprod. Fert., v.8, p.39-47, 1964.

FREEDMAN, S.L.; AKUFFO, V.G.; BAKST, M.R. Evidence for the innervation of sperm storage tubules in the oviduct of the turkey (Meleagris gallopavo). Reproduction., v.121, p.809- 814, 2001.

FRIESS, A.E.; SINOWATZ, F.; WROBEL, K.H. et al. The uterovaginal sperm host glands of the quail (Coturnix coturnix japonica). Cell Tissue Res., v.191, p.101-114, 1978.

Arq. Bras. Med. Vet. Zootec., v.65, n.1, p.19-28, 2013
FUJII, S.; TAMURA, T. Location of sperms in the oviduct of the domestic fowl with special reference to storage of sperms in the vaginal gland. J. Fac. Fish. Anita Husb. Hiroshima Univ., v.5, p.145-163, 1963.

GILBERT, A.B.; REYNOLDS, M.E.; LORENZ, F.W. Distribution of spermatozoa in the oviduct and fertility in domestics hen.: histochemistry of the uterovaginal sperm hosts glands of the domestic hen. J. Reprod. Fertil., v.16, p.433-444, 1968.

GOODRICH-SMITH, M.; MARQUEZ, B.J. Estimation of the numbers of sperm storage tubules located at the uterovaginal junction in turkey oviduct. Poult. Sci., v.57, p.1139, 1978.

KING, A.S. Apparatus urogenitalis. Handbook of Avian Anatom: Nomina Anatomica Avium. 2nd. ed. Cambrigde, Mass.:Nuttall Ornithological Club, 1993. 329-397p.

KING, L.M.; BRILLARD, J.P.; GARRET, W.M. et al. Segretation of spermatozoa within sperm storage tubules of fowl and turkey hens. Reproduction, v.123, p.79-86, 2002.

LEV, R.; SPICER, S.S. Specific starning of sulphate groups with alcian blue at low $\mathrm{pH}$. $J$. Histochem. Cytochem., v.12, p.309, 1964.

LILLIE, R.D.; FULLMER, H.M. Histopatologic technic and practical histochemistry. 4.ed. New York: McGraw-Hill, 1976. 942p.

McMANUS, J.F.A. Histological demonstration of mucin after mucin after periodic acid. Nature, v.158, p.202, 1946.

MELLO, H.E.S. Aspectos morfológicos das glândulas hospedeiras de espermatozoides na perdiz, Rhynchotus rufescens (Temminck, 1815) (aves, Tinamiformes) nas fases do ciclo reprodutivo. 2000. 50f. Dissertação (Mestrado em Zoologia) - Pontifícia Universidade Católica de Minas Gerais, Belo Horizonte.

MICHALANY, J. Técnica histológica em anatomia patológica. São Paulo:Editora Pedagógica e Universitária Ltda., 1980. 277p.

MIRANDA, J.L.P.S.; OLIVEIRA, C.A.; MAHECHA, G.A.B. Aspectos morfológicos, histoquímicos e de morfometria dos túbulos armazenadores de espermatozoides da fêmea do peru Meleagris gallopavo. Arq. Bras. Med. Vet. Zootec., v.61, p.72-79, 2009. 
MOWRY, R.W. Alcian blue technic for the histochemical study of acid carbohydrates. $J$. Histochem. Cytochem., v.4, p.407, 1956.

MORAES, C.; BARALDI-ARTONI, S.M.; PACHECO, M.R. et al. Histologia e morfometria das glândulas das junções infundíbulo-magno e útero-vagina de codorna doméstica. Cienc. Rural, v.39, p.421-427, 2009.

MÓRI, C.; GARCIA, E.A.; PAVAN, A.C. et al. Desempenho e rendimento de carcaça de quatro grupos genéticos de codornas para produção de carne. Rev. Bras. Zootec., v.34, p.870-876, 2005.

PAL, D. Histochemistry of the uterovaginal junction with special reference to the sperm-host glands in the oviduct of the domestic duck. Folia Histochem. cytochem., v.15, p.235-242, 1977.

RENDEN, J.A.; MAY, E.B.; BENOFF, F.H. Histochemistry of uterovaginal sperm-host glands in Japanese Quail (Coturnix coturnix japonica) with reference to the period of oviposition. Poult. Sci., v.60, p.2529-2535, 1981.

RODRIGUES, C.A.T. Morfologia do oviducto esquerdo da codorna comum, Nothura maculosa (Temminck, 1815) (aves, Tinamiformes), nas fases de secreção, regressão e proliferação. 1996. 229f. Dissertação (Mestrado em Morfologia) - Instituto de Ciências Biológicas, Universidade Federal de Minas Gerais, Belo Horizonte.
SAMPAIO, I.B.M. Estatística aplicada à experimentação animal. Belo Horizonte: Fundação de Ensino e Pesquisa em Medicina Veterinária e Zootecnia, 1998. 221p.

SCHUPPING, G.T.; VAN KREY, H.P.; DENBOW, D.M. Ultrastructural analysis of uterovaginal sperm storage glands in fertile and infertile turkey breeder hens. Poult. Sci., v.63, p.1872-1882, 1983.

TINGARY, M.D.; LAKE, P.E. Ultrastructural studies on the uterovaginal sperm-host glands of domestic hen, Gallus domesticus. J. Reprod. Fertil., v.34, p.423-431, 1973.

VAN DRIMMELEN, G.C. "Spermnests" in the oviduct of the domestic hen. J. African., Pretoria, v.17, p.42-52, 1946.

VAN KREY, H.P.; OGASAWARA， F.X.; PANGBORN, J. Light and electrón microscopic studies of possible sperm gland emptying mechanisms. Poult. Sci., v.46, p.69-78, 1967.

VERMA, G.P.; CHERMS, F.L. Observations on the oviducts of turkeys. Avian Dis., v.8, p.19-26, 1965. 